\title{
LA REPRESENTACIÓN DEL ESPACIO FAMILIAR COMO OMINOSO EN LA LITERATURA COSTARRICENSE: DE LA RUTA DE SU EVASIÓN A LARGA NOCHE HACIA MI MADRE
}

Carolina Sanabria

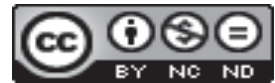

Esta obra está bajo una licencia Creative Commons 



\title{
LA REPRESENTACIÓN DEL ESPACIO FAMILIAR COMO OMINOSO EN LA LITERATURA COSTARRICENSE: DE $L A$ RUTA DE SU EVASIÓN A LARGA NOCHE HACIA MI MADRE
}

\author{
THE REPRESENTATION OF THE FAMILIAL SPACE AS OMINOUS IN \\ COSTA RICAN LITERATURE: FROM LA RUTA DE SU EVASIÓN TO \\ LARGA NOCHE HACIA MI MADRE
}

\begin{abstract}
RESUMEN
En la literatura costarricense, el tema de lo familiar ha sido tratado con cierta irregularidad desde sus inicios. Pero con la publicación de La ruta de su evasión (1949) de Yolanda Oreamuno, se produce un quiebre no solo a nivel temático, sino formal, en cuanto a la construcción de un universo íntimo desde un discurso de lo femenino a partir de técnicas dentro de las que sobresale el monólogo interior. La casa aparece como un espacio asfixiante que hace de los miembros de la familia seres extraños, que provoca sus respectivas evasiones, con lo que termina constituyéndose como un armazón hueco, unheimlich por cuanto funciona como instancia de represión. Esta atmósfera fantasmal en el mismo plano familiar es reelaborada, más de sesenta años después de su publicación, por otra novela, Larga noche hacia mi madre (1913) de Carlos Cortés, donde la casa adquiere matices más fantasmales que en la obra de Oreamuno. Sin embargo, en ambas lo siniestro emana desde la figura típicamente cohesionadora: la madre, y termina siendo una figura que está ligada a una función que niega la protección, de modo tal que solo su muerte puede permitir la liberación de sus miembros. Lo que se pretende, por tanto, es abordar la representación de lo familiar como ominoso en dos novelas que responden a momentos distintos de la literatura costarricense.

Palabras clave: madre, ominoso, monstruo, casa, narración.
\end{abstract}

\begin{abstract}
In Costa Rican literature, the theme of the family has been treated with some irregularity since its inception. But with the publication of La ruta de su evasión (1949) by Yolanda Oreamuno, a formal and thematic break occurs, in terms of the construction of an intimate universe from a discourse of the feminine, using techniques like internal monologue. The house appears as a suffocating space that turns family members into strangers, making them want to scape, and ends up becoming a hollow shell, unheimlich because it works as instance of repression. This spooky atmosphere is reworked at the household level, more than sixty years after its publication, by another novel, Larga noche hacia mi madre (1913) by Carlos Cortes, where the house becomes more ghostly than in the work by Oreamuno. However, in both the sinister element emanates from the typically cohesive figure of the mother, who ends up being a figure which is linked to a function that denies protection, so that only her death could allow the release of its members. The aim, therefore, is to address the representation of the familial as ominous in two novels that respond to different times of the Costa Rican literature.
\end{abstract}

Key words: mother, ominous, monster, house, narration.

\footnotetext{
Dra. Carolina Sanabria. Universidad de Costa Rica. Profesora Catedrática de la Escuela de Estudios Generales. Costa Rica.

Correo electrónico: csanabriacr@yahoo.com
}

Recepción: 07- 04- 2015

Aceptación: 19- 06- 2015 
En la tradición de la narrativa costarricense, el tema familiar ha sido tratado con cierta irregularidad desde sus inicios. La razón básica parece residir en el hecho de su dificultad de encajar en el proyecto de construcción de la literatura nacional, dentro de la pauta de la literatura costumbrista en sus inicios o la de denuncia social de la prolífica década de los 40. Los temas canónicos del lenguaje emergente se habían venido centrando en torno a conflictos sociales, si bien ha habido una paulatina incorporación del intimismo en la narrativa conforme su desarrollo en el siglo XX.

Como bien es conocido, tomó décadas en reconocerse que La ruta de su evasión (1949) de Yolanda Oreamuno suponía una ruptura con respecto a la novedosa forma de narración de entonces: antirrealista y antirreferencial, con ausencia de linealidad discursiva, en la que la omnisciencia se mezclaba con los flujos mentales de algunos de sus personajes. Esta particular estructura daba pie a estilismos como la morosidad en la descripción o el influjo de lo inconsciente que lograba colarse en el discurso de carácter proustiano -obsesión declarada de la autora (de Vallbona, 1987, p. 194)- apenas entonces en boga. La consecuencia inmediata se traducía en una renovación del lenguaje literario, que incorporaba además el multiperspectivismo en el desarrollo de un tema aún no trabajado por acaso polémico. Parte de la relevancia de La ruta... reside en el hecho de haberse constituido como una de las novelas que proponen una destrucción de la imagen idílica de la familia (Ovares et ál., 1993, p. 273). 1 Hasta entonces en el desarrollo de las literaturas nacionales era común que el conflicto se enmarcara en la confrontación del espacio de afuera (público, masculino) y el de adentro (la esfera privada, femenina) (Franco, 1986, p. 35), constituido en una extensión de la madre. El consenso admitido por la historiografía crítica propone que, al concentrarse en el mundo interior de los personajes, La ruta... sea una novela que hubiera carecido de antecedentes en la literatura del país (Ovares et ál., 1993, p. 264), donde el adentro es motivo suficiente de complejidad.

El precedente indiscutible se remonta a As I Lay Dying (1930) de William Faulkner. Esta primera novela del escritor sureño no sólo había sentado las bases técnicas de vanguardia del fluir de la conciencia (stream of consciousness) reelaboradas por diversos escritores hispanoamericanos, sino la base argumental del tema de la madre agonizante o muerta que logra aglutinar a los miembros dispersos y divergentes de una familia -los cuales asimismo quedaban revelados, antes que en sus actos, en la expresión individual de sus miserias en torno al tortuoso viaje de entierro-. En el caso de Oreamuno, los acontecimientos también se articulan a partir de esa visión esteroscópica que ofrece una pluralidad perceptiva sobre un mundo narrado desde la conciencia de Teresa, el personaje central (Robles-Mohs, 1988, p. 52). Pero sin lugar a dudas la primera novela en haber abordado la problemática familiar en la narrativa nacional es La ruta... desde un planteamiento disfuncional como un espacio execrable, ominoso.

La familia es descrita como lugar de pérdidas irrecuperables, como constata la misma vida de la autora desde su pubertad -si bien cabe considerar el peligro de los enfoques personalistas o biografistas que señala Mackenbach (2007, p. 15) al respecto de que el peso de lo biográfico ha sido determinante en la recepción crítica de la novela una vez que fue reivindicada en los estudios literarios-. Pero esa advertencia, hecha a su vez eco de la de Chase -sobre una necesidad de investigar más a fondo "la distancia sutil" entre el mundo personal de Oreamuno y la expresión novelística (2006)-, tampoco debería conducir a su extremo, esto es, a la trampa de soslayar las construcciones del yo público del autor en su texto. ${ }^{2}$ 
Más de medio siglo transcurrido, Carlos Cortés publica, desde una tesitura semejante, otra novela con un tema y estructuración análogos - la problematización de la maternidadbajo la misma clave de la novela autobiográfica -aunque en este caso con el anonimato del autor que fuerza el equívoco inherente a este tipo de escritura del yo-. Con el título de Larga noche hacia mi madre (2013), la historia mantiene el tema de la agonía de una madre desde un personaje narrador que mantiene un imborrado malestar. Desde este punto de vista, hay una marcada diferencia con La ruta... en tanto esta ofrece cierto tono de novela de tesis -por lo demás, no inusual en un momento, especialmente político, que se prestaba a ello-, de ideas polarizadas encarnadas en los personajes y confrontados dialógicamente. Se trata de una variedad del autobiografismo que viene a funcionar como una fórmula válida, "un buen bálsamo o pócima maligna”, como lo había afirmado Manuel Alberca (2007, p. 109), "para hablar de sí mismo y para exorcizar sin mayores riesgos aquello que todavía próximo o reciente hace sufrir o lo hizo en el pasado". El enfoque resulta acorde con la tónica característica de la generación de escritores de la década de 1980 en cuanto al predominio de protagonistas derrotados, la violencia como forma fundamental de la relación social y la ausencia de salida ante los problemas vitales (Rojas y Ovares, 1995, p. 241), a diferencia de la indeterminación espacio-temporal de La ruta...

En su caso el desencanto ha venido constituyéndose en el eje o más bien el estilo de su narrativa, como en su anterior novela Cruz de olvido, cuyo conflicto se articulaba a partir de la imagen de una ciudad grotesca y siniestra: "un mundo subterráneo desfigurado por el mal, la corrupción, el terror y la violencia" (Quesada, 2012, p. 133). Ese clima nauseabundo que centraba su desencadenante en el núcleo político ahí derivaba endogámico por cuanto reducido, al igual que el familiar, referencia residual que se reconstruye en el eje central de Larga noche...: "Todos estábamos presos en el mismo redil incestuoso, porque la única maldición peor que la geografía es la familia" (Cortés, 1999, p. 20). Solo que en la última novela de Cortés la narración es de un potente intimismo empleado desde otra estrategia y modalidad, el relato testimonial predominante en primera persona. ${ }^{3}$ Sin embargo, lo hace de manera fragmentada porque la narración se funda en la memoria parcelada en trozos epistolares y legajos oficiales articulados desde distintos saltos temporales -estrategia que también seguía La ruta...- los cuales van del pasado remoto individual al presente inmediato como un viaje al fondo del dolor. ${ }^{4}$

La ruta... y Larga noche... tienen en común esta dinámica donde el espacio hogareño se concibe como un lugar reprimido y unheimlich, un concepto que en 1912 Freud había introducido para referirse primeramente a la conciencia humana y que luego se estiliza como rasgo artístico y literario (Harari, 1998) fundado en el orden armónico, domesticable, lo que "siempre fue familiar a la vida psíquica y que sólo se tornó extraño mediante el proceso de su represión” (Freud, 1976, p. 46). Lo represivo es lo que por definición en Freud pertenece al ámbito hogareño. Se borda por tanto como espacio topográfico, en referencia a casos donde la experiencia del horror no procede de fuera, como en la tradición generalizada y predominantemente costumbrista de la literatura costarricense, sino de dentro de la casa familiar. Y en tanto se pierde el sentido de la estabilidad, seguridad y bienestar que da paso al efecto de extrañamiento, esta termina convertida en sede de lo monstruoso. Es un lugar que, como sostiene Hock-Soon Ng (2004, p. 16), “can assume monstrous proportions when it becomes a repository for the subject's unconscious; the home becomes the locus of the subject's projected anxieties, bringing into relief the repressed other and (possibly) transforming the subject into a monster". 
En esa atmósfera coinciden ambas novelas, que construyen una imagen del espacio íntimo, de refugio, y lo convierten en el menos seguro de los lugares. Así lo mencionaba Oreamuno cuando recreaba la impresión que podía generar en un hipotético visitante, donde la hostilidad no solo circulaba entre sus propios miembros, sino que también irradiaba hacia los ajenos. Si la casa entonces resultaba un sitio inhabitable para el morador, para el invitado ajeno -más objetivo por cuanto distanciado- era a todas luces inhospitalario:

\begin{abstract}
Cuando un visitante llegaba solo, el problema para el infortunado era más grave porque la ignorancia de su persona era entonces general. Si se trataba, por otra parte, de algún estudiante a quien traía uno de los muchachos, quien lo llevara, participaba del frío recibimiento. Después del forzoso saludo falso y cortés de don Vasco, éste reanudaba sus paseos, y el extraño pasaba al más absoluto anonimato. La comida se servía frente a sus ojos sin que se le invitara; el que estudiaba apoltronado en un rincón silenciaba a gritos la conversación del visitante; otro lo desalojaba de su sitio sin preámbulos. Después de soportar aquellas impertinencias entre espantado y embrutecido, el forastero se marchaba decidido a no volver jamás. (Oreamuno, 2010, pp. 47-48)
\end{abstract}

De ahí que antes que lugar de acogida, la casa se convierte en punto de expulsión, lo que ocurre también en el texto de Cortés. En ese sentido, ambas novelas aluden desde su título el itinerario de un viaje inequívocamente de tipo interior. En La ruta... el posesivo que contiene es ambiguo ex profeso: cada uno de los personajes que habita ese lugar idea su propia estrategia -más o menos extrema- para escapar del entorno asfixiante: el alcoholismo en el caso del patriarca Vasco, la masturbación en Álvaro, ${ }^{5}$ la disciplina férrea autoimpuesta por Roberto, el suicidio ejecutado por Gabriel hacia el final del relato. Por su parte, en Larga noche... la idea del trayecto está dada por el sustantivo 'noche', de una condición temporal (durativa) -que adquiere prolongación con el adjetivo, de alta carga simbólica con el tropo literario de noche oscura espiritual- antes que atmosférica. Así sucede con la respectiva fuga interior de su personaje que corre como odio canalizado a través del ejercicio de escritura.

La fenomenología de este espacio es sutil, la casa se figura desmaterializada, como un núcleo básico que reúne a la familia o aloja su historia. A diferencia de su marido y sus hijos, la evasión, para el personaje femenino de Teresa no está fuera, sino a lo interno de sí: desde el inicio del matrimonio, ella concentra su atención y energías en la casa, la misma que más tarde habrá de provocar su movimiento contrario, a saber, la huida definitiva de los hijos mayores. ${ }^{6}$ Por tanto, la novela se sostiene sobre una paradoja, la de que el núcleo que alberga a la familia es igualmente el motivo de su sacrificio, como le reprocha Gabriel, "un cascarón hueco donde no vive nadie" (Oreamuno, 2010, p. 290), "esa armazón [donde] los seres se desintegraban a su lado sin que ella lo notara [...] que también estaba deshaciéndose" (Oreamuno, 2010, p. 327). Como espacio tradicionalmente femenino, tanto la casa como la madre se disuelven, se desgastan en el transcurrir de la acción. La ruptura se dirige a una existencia no propiamente como espacio físico, sino más bien como lugar desde donde hablan los personajes (Rojas y Ovares, 1995, p. 140). No se le concibe por tanto de manera realista, sino como "centro de emisión de la mayor parte de los discursos, el espacio propio de la palabra de los personajes" (Ovares et ál., 1993, p. 266) que no dialogan ni se interrelacionan ni se trasforman, simplemente fluyen o circulan sin modificarse. Es lo propio de un texto que se sostiene por cierto sobre la incomunicación ${ }^{7}$ en la que sus personajes se abocan a exponer, ilustrar o defender una tesis o teoría conceptual desde posiciones claramente argumentativas y polarizadas. ${ }^{8}$

La casa en Larga noche... no es ese cascarón hueco de La ruta..., sino que, en virtud de su misma inmaterialidad, se identifica con la otra por construir un ámbito esencialmente fantasmal, tenebroso, como recuerdo relacionado con el pasado lejano, porque la acción presente 
se halla prioritariamente en el hospital. Si se quiere encontrar alusiones propiamente a la casa en la narrativa del autor, sería pertinente remitirse a Cruz de olvido, que a su modo podría pensarse como antecedente de Larga noche... porque relata una misma situación conflictiva, próxima al hundimiento físico (que también es metafórico de sus habitantes: la madre y las tías) como figura la surrealista inundación de agua por toda la vivienda ante la inercia de sus habitantes. De hecho, Cruz de olvido cierra el episodio familiar con el internamiento de la madre en el hospital psiquiátrico.

La casa entonces aquí se concibe como el lugar que cobija tanto los miembros que han pasado por ella o se han emparentado con aquellos o vinculado con objetos que quedan convertidos en no recuerdos por los miembros de la misma familia. Pero ante todo constituye el espacio femenino por excelencia, no solo la de la madre, sino también la de la abuela (la madre del padre), que acoge las pertenencias del hijo, prematuramente muerto ${ }^{9}$-violentamente asesinado-, de manera por cierto semejante al de Oreamuno, que falleció antes de que esta cumpliera un año. En el caso de Larga noche..., estas posesiones dan fe tanto de su dimensión pública -trofeos, medallas, noticias y diplomas- como privada -las joyas sin valor, los cofrecillos llenos de papeles y chucherías, las americanas que termina apropiándose el tío-. La casa no solo es el lugar que contiene estos objetos, sino que los fagocita, porque asimismo adquiere un carácter tan inmaterial como la memoria, asociada a los recuerdos que no son, que tienen mayores facultades de desvanecimiento que lo sólido en el aire.

En Larga noche..., que converge en el tópico de la desintegración de la casa familiar como sucedía en la de Oreamuno, la muerte entonces de la madre conduce a un desfile de los inimaginados miembros de la extensa estirpe incluso pertenecientes a una generación que cronológicamente vendrían a resultar coincidentes con los de La ruta... Pero hay una diferencia de matiz: en Larga noche... son sujetos, en su mayor parte, ${ }^{10}$ que van elaborándose decididamente como espectrales, revividos por el recuerdo, presentados como sombras desdobladas en otros, en cierto modo variaciones del narrador y personaje principal que no dejan de tener cierto efecto inquietante por su multiplicación hasta la imprecisión. Su recuento -onomástico y fisiológico- destaca por una voluntaria resistencia al parecido físico de sus hijos. Cada uno, entonces, diseña aquí también sus propias tácticas de evasión: el protagonista José Enrique Expósito no se reconoce en el padre y por tanto, lo llama por su hipocorístico 'Quique' -que rompe con la designación filial aunque mantiene el tono de camaradería-, y como si no fuera suficiente se precia de carecer de semejanza física y niega nominal y doblemente su filiación: tacha el segundo nombre de su padre y de paso el segundo apellido de su madre; el medio hermano Juan Enrique también se resiste a la identificación y prefiere que lo llamen 'Johnny'. Esta forma de nominación del narrador para la caracterización de su padre se alterna hacia los últimos capítulos con otra: la inicial de su nombre (Q.), ${ }^{11}$ como si con ello se sugiriera un desvanecimiento próximo y definitivo.

Solo parece inmune -acaso por lejanía o incontaminación- "el otro hermano" descubierto hacia el final, José Enrique Morales, paradójicamente el doble más fiel: "Como mi padre en otro maldito cuerpo", dice el narrador al conocer a este último que se suma a la lista de hermanos imprevistos. Es un hecho que no entraña tanto lo siniestro en sí mismo por cuanto abre la posibilidad de la repetición imprecisa de un doble imperfecto, de un socias grotesco, como continúa: "No es mucho más fornido, pero sí más alto, y con el modo de andar característico de Quique, cargado de hombros. Un recuerdo inventado, hecho de recuerdos y relatos ajenos. Al verlo me pregunté si no habría otros hijos de Quique por ahí" (Cortés, 2013, p. 173). La idea del doble, tradicionalmente inquietante por lo que Freud (1976, p. 34) había visto 
como una partición y sustitución del yo, contiene la amenaza de desposesión de la identidad ${ }^{12}$ contenida en Cortés y se construye desde la fenomenología de un ser emergente que roza por tanto lo fantasmal -la aparición casi súbita, "como si hubiera resucitado" (Cortés, 2013, p. 173) en una ubicuidad dada por la incertidumbre de la reproducción-. Así resulta la variante de una de las posibilidades siniestras que ofrece la familia, la de la reduplicación del sujeto mismo, desaparecido antes y aparecido de nuevo, como si se tratara de un espectro porque el original no existe. Es el padre vuelto a la vida sin ser exactamente; el fantasma no hace sino revivir el primitivo terror a los muertos que es el lugar en donde para Freud reside la esencia de lo siniestro (Freud, 1976, p. 48).

No tienen esta carga ominosa los nombres repetidos y sus identidades en La ruta... pero sí sobradamente simbólica, lo que hace de esta novela un texto más artificioso y afectado. Por ejemplo, no es extraño encontrar algunos de sus personajes dotados de reminiscencias bíblicas, como Teresa, que en una de sus dimensiones, la sacrificial, evoca a la conocida religiosa y mística del siglo XVI, o Gabriel, de innegable referencia al arcángel de la buena nueva que porta aun cuando esta contenga la paradoja de su propia aniquilación. El mismo Esteban que condensa la autoinmolación del primer mártir cristiano para la salvación del culpable, subraya la paradoja, su propio rival. Pero por encima de ellos se destaca otro de gran bastedad simbólica, Aurora, un personaje prácticamente plano que resalta por constituirse en una presencia radiante en contraste con la lúgubre casa y que presagia el final positivo y liberador de su nombre.

No solo en Larga noche..., sino en La ruta ... interviene un poderoso componente de la memoria, ligado a la evocación de un pasado a través de los saltos temporales y de los cambios de perspectiva. Ya se ha dicho que la novela de Cortés presenta una serie de sujetos familiares, en su caso bastante más diluidos que los de La ruta..., aunque el trayecto que recorren está articulado alrededor de un mismo suceso desencadenante: la agonía de la madre, en un caso enfocada en su calidad de sostén básico y en otro como fragmento imprescindible que en el acto de desdibujarse suscita una compleja genealogía de sujetos desmembrados. No tienen estos una consistencia equivalente en la novela de Oreamuno, arquetípicos y deshumanizados (Ovares et ál., 1993, p. 270). Pero en ambos textos viene a ser un hecho común el mecanismo de elaboración del padre como figura ligada a la negatividad, en Oreamuno por opresiva y despótica y en Cortés por ausente -incluso al punto de llevar a su narrador a plantear que no le perdona su falta, el "haberse dejado matar" (Cortés, 2013, p. 189)-. De esta manera el carácter ominoso se revive, se reproduce en el mismo protagonista como padre a su vez que tiene la conciencia de haber cumplido la misma edad que alcanzó el suyo al morir.

Parece claro que La ruta... propone una crítica al entorno patriarcal, con un planteamiento de la figura masculina como opresiva y dominante, organizada "de acuerdo con una oposición entre dos papeles: el de victimario (masculino) y el de víctima (femenino)" (Ovares et ál., 1993, p. 267) -con la sola excepción de Esteban y acaso del nulificado y simplificado Álvaro, reducido a algunas menciones marginales-. La mujer, en sus distintas modalidades -esposa, novia, amiga-, se le opone, pero desde una dinámica que no deja de enmarcarse en un campo de polarización -que antes de operar en demérito de la novela, cabría ver como una anticipación a la emergencia de una nueva concepción de lo femenino que se estaba gestando entonces-. ${ }^{13}$

Ya se ha planteado que Teresa no deja de ser un personaje responsable y víctima de unos actos que la dinámica patriarcal lleva a cargar hasta el lecho de muerte como consecuencias de lo que abusivamente se ha hecho depender de ella: del destino de sus 
miembros y su consecuente alienación. Es probable que el hecho de que se erija claramente en víctima de las voluntariedades de su autoritario marido, aunado a su condición agonizante, matice el que pueda considerarse su auténtica magnitud: la de una pieza que posibilita y complementa el funcionamiento del mismo esquema represivo. Como es evidente, el discurso está escrito desde una perspectiva masculina, y hace algunos años Rima de Vallbona se refirió a la composición de una serie de grupos semánticos que llamó lexías conceptuales detectables en el discurso de su más clara resonancia, Aurora. En estas "llama la atención que pertenecen a la escritura femenina y, sin embargo, se pueden calificar de discurso patriarcal, ceñido a los cánones falogocentristas que han predominado en el tratamiento del tema de la mujer en literatura y que ya se han convertido en lugares comunes" (de Vallbona, 1987, p. 210). Estas lexías funcionan en el esquema patriarcal que asume en la figura materna la instancia en la que recae la responsabilidad del destino de todos los miembros de la familia, en un problemático sentido redentor: "Ella pudo salvar del alcoholismo a su marido, de la insensibilidad a Roberto, de la locura a Gabriel, del embrutecimiento a Álvaro, pero sólo había edificado una casa que también estaba deshaciéndose" (Oreamuno, 2010, p. 327), lo cual vendría a contrariar el cuestionamiento de esa dinámica patriarcal que se le ha atribuido a la novela. A lo largo de sus páginas se reafirma un sostenimiento del modelo confirmado una generación después, como lo reproducen las parejas de sus hijos mayores, Cristina y la misma Aurora. Y aunque esta última decida romperlo al final no sin cierta inmotivación diegética, ${ }^{14}$ el modelo femenino que encarna Teresa sigue siendo una fuerza tan negativa, tan ominosa, aunque sutil, pero sobre todo tan contundente como el propio Vasco.

La amenaza que contienen ambos relatos en relación con la casa familiar queda plasmada en torno a lo que se elabora en última instancia como lo femenino en un sentido que no deja de estar asociado a lo monstruoso, a lo ajeno, a la negación de la función protectora y al aglutinamiento en torno suyo de los miedos más profundos del hombre (Cortés, 1997, p. 41). No por estar directamente victimizada a una circunstancia represiva, como en el caso de Vasco, la madre de la novela de Cortés deja de tener una menor densidad de lo monstruoso. Solo que en La ruta... es más sutil en tanto forma parte de un discurso patriarcal que sobrecarga en su función a costa de ella. Este carácter ominoso que comparte en Larga noche... se acentúa con la situación escatológica de la madre en sus últimos días, y es lo que explica que la liberación se produzca necesariamente a partir de la noticia de su muerte. "La primera llamada de mi prima Sara, dos o tres semanas antes, pareció el anuncio cercano a la liberación final" [cursiva agregada] (Cortés, 2013, p. 16), dice al principio el narrador de Larga noche... Algo semejante se producía en el caso de Teresa, cuyo desenlace final daba paso al derrumbamiento de la casa y al relevo optimista y redentor de Aurora, que por lo demás no constituye elemento primario del núcleo familiar. Así era confirmado por esta cuando al mirar el cuerpo de Gabriel tendido en la cama a su lado era capaz de no sentir ninguna pena, "como si nunca el amor la hubiera poseído, como si no hubiera sido víctima del terror, como si nada de ella estuviera relacionado con el suicida" [cursiva agregada] (Oreamuno, 2010, p. 394), es decir, como la extraña o la ajena que nunca dejó de ser.

Pero, aun en medio del delirio de su agonía, Teresa no llega a perder conciencia de sí, es más, sus últimos estertores resultan el momento (el clímax de la acción) en el que adquiere mayor lucidez; Lily por su parte alcanza niveles patológicos de esquizofrenia, diagnóstico que más adelante se dirá que se había manifestado previo al nacimiento del hijo. De este modo hay una diferencia de matiz: Larga noche... propone una negatividad distinta de la madre, 
particularizada por la incorporación del componente de la demencia que el desconcertado hijo desde pequeño ve desarrollarse, que lo expone y avergüenza ante el resto de sus compañeros de la escuela. Entonces, por un instante se tienta la posibilidad de que la locura podría desempeñarse como atenuante de esos actos que marcaron al hijo. Pero las cosas no funcionan precisamente de ese modo.

La clave parece más bien dirigirse a la reivindicación de la conciencia, mediada por la palabra, como forma de canalizar las fuerzas enfrentadas en el espacio familiar ominoso. $L a$ ruta... contenía una pugna por la liberación de la palabra que resultaba en vano porque daba como resultado una yuxtaposición de monólogos (Rojas y Ovares, 1995, p. 141) que no logran interrelación más que con el yo mismo desdoblado en su alternancia (Robles-Mohs, 1988, p. 51). Teresa lograba desatar la conciencia en su agonía y su discurso encontraba respuesta en Aurora, pero sin manera posible de desarrollar una interacción dialógica o auténticamente integradora con esta ni tampoco con el resto de personajes femeninos, menos aún los masculinos -los hijos- con los que se establece una relación de oposición según se dijo que reconocían Ovares et ál. (1996). Es evidente que a la larga, también resultan perjudicados los varones porque la dinámica hace recaer prácticamente de manera exclusiva sobre las mujeres la función de sensibilización que en cambio Cortés demuele aún más radical. ${ }^{15}$ Por eso, aun cuando hacia el desenlace Aurora adquiera emancipación ante las agresiones de Gabriel, su actitud -de una indulgencia cercana a la renuncia y al padecimiento en la mayor parte de la historia- no termina de resultar verosímil con su actitud y pasividad anterior, encontrando correspondencia en la pasividad pragmática de Teresa.

Es así como el discurso lúcido de Teresa en su monólogo interno, decididamente innovador en el panorama literario costarricense de la década de los 40, se había constituido la técnica idónea para tratar el mundo de los personajes a lo interno de una atmósfera intimista, y a ella vuelve Cortés para cerrar su último capítulo, en abandono paulatino de la narración testimonial que caracterizaba la novela. Durante su transcurso el narrador protagonista se venía debatiendo en una lucha interna por la redención de sí mismo, que finalmente llega a resolver a partir de esa estrategia narrativa que designa como desatar los labios y da título al último capítulo. Se podría considerar tal técnica como una variación del monólogo interior, a partir de un recurso de fusión discursiva -lograda por las oraciones inconexas, interrumpidas, fragmentadas, las cuales se remontan al momento determinante y traumático: el del nacimiento del hijo-. De este modo se recrea la situación cercana a la retrospección al momento del parto en donde participan varias instancias -no todas determinadas ni determinables-aglutinadas en torno a una sola voz ${ }^{16}$ que concita una búsqueda de la verdad a través de la escritura.

En cambio, en la novela de Cortés, donde la madre no manifiesta nunca su subjetividad, desatar los labios es el mecanismo que el hijo encuentra posible -cuyo flujo discursivo había venido dominando la narración a lo largo de toda la novela- para prodigar, en medio del más infinito e incomprensible pesar, otro escenario, por encima de su carácter irrealizable: cediendo la palabra a lo que la demencia impide pronunciar, fusionándose en el discurso de la locura, el único lugar desde el cual es posible acceder al del momento primigenio de su nacimiento, al de la maternidad.

\section{Notas}

1. Como ilustraba el texto costumbrista de Adolfo Herrera, Juan Varela (1939), a que se refirió la misma escritora en uno de sus artículos como representación del campesino costarricense y del concho de 
Echeverría: "Juan Varela [...] es la primera página en este mito religioso de la tierra muy repartida, la casita pintada de blanco y azul y el pequeño propietario de chanchos y gallinas que lleva al cuello un pañuelo 'colorado"' (Oreamuno, 2011, p. 52).

2. De lo que cabe añadir que tampoco es el objeto del artículo. La perspectiva que abunda en la eventual serie de transgresiones de la autora con respecto a los cánones de su época podría ser más pertinente de plantear en la ficción, como lo hizo Sergio Ramírez en La fugitiva (2011). En el estilo de una mise en abyme, la historia se sustenta sobre la idea de que la inmencionada novela (La ruta..., aquí con el título de La puerta cerrada) tiene mucho de autobiográfica en virtud de las referencias comprobables a una vida familiar desmembrada desde una narración dada a partir de una estructura que reproduce la dinámica y la visión de lo femenino.

3. Excepto puntuales inserciones en cursiva del lenguaje epistolar donde el narrador cede el discurso: el capítulo X procede de la enfermera que atiende el parto del protagonista, el capítulo XIII es una carta del tío Fernando a su esposa, y el capítulo XXI, firmada por su padre y extraviada (lo que remite a la estrategia del manuscrito encontrado para dotar de verosimilitud a la historia). Estas otras fuentes de enunciación permiten dar una visión más amplia, más estereoscópica, como en La ruta..., del espacio familiar, pero también más fragmentada, las piezas que el narrador trata en vano de articular como una historia coherente.

4. Es una de las rupturas más sobresalientes de La ruta... en cuanto a la trayectoria anterior, dominante en la literatura nacional del costumbrismo y del regionalismo, como señala Mackenbach: la construcción del espacio no a partir de descripciones narrativas de espacios físicos extratextuales sino monologados y dialogados, de manera tal que "estas representaciones de los espacios físicos se dan a través del espacio interior de los personajes y no en el relato 'directo' del narrador" (2007, p. 16).

5. Como patológica, aunque la novela no ofrece mayores detalles y la posible complejidad del personaje de Álvaro queda reducida por esa práctica, de lo que solo cabe añadir que es una percepción de la sexualidad deudora de su época, planteada como un uso del cuerpo condenable.

6. Como le dice Roberto a su padre antes de abandonarla: "Siento que no respiro, todas mis facultades están presas, vivo en una indefinible angustia y comprendo que sólo la salida de este ambiente puede devolverme la deseada normalidad" (Oreamuno, 2010, p. 212).

7. En cambio, en Larga noche... el tema de la incomunicación no tiene lugar; incluso no llega siquiera a plantearse voluntad de expresión más que del protagonista. Los contactos que se establecen con el narrador protagonista, como el de Johnny, son propiciados más como necesidad mendicante por su parte.

8. Propio, como ya se dijo, de la narrativa precedente en las llamadas novelas de tesis en la literatura costarricense como la fundacional El problema (1899) de Soto Hall o El árbol enfermo (1920) de Carlos Gagini.

9. Cabría especular, en tal dirección, que en la novela de Cortés la falta paterna bien podría haber dado lugar a su respectiva idealización. Sin embargo no funciona de ese modo, porque el mismo narrador revela que su progenitor, inopinadamente asesinado cuando sólo tenía tres meses de gestación, había sido un sujeto infiel en sus relaciones personales. Cuenta que tenía con varias amantes - de lo cual dan constancia los hijos a su haber- y un divorcio pendiente con la madre una vez aquel hubiera nacido, de manera tal que la presencia del padre estaría lejos de haber garantizado una matización de lo traumático (Sanabria, 27/10/2013, p. 11). Una fotografía lo describe como "una figura autoritaria y lejana" (Cortés, 2013, p. 73), de modo que el desvanecimiento de la posibilidad de la existencia paterna como resguardo de una suerte distinta agrava doblemente la sensación de orfandad manifestada a lo largo de toda la novela. Por lo demás, el hecho de que el narrador de esta novela -así como el de Cruz de olvido- no se refiera nunca a las causas directas del incidente, contiene implícita una de las circunstancias de la novela autobiográfica, deudora de la idiosincrasia liberal, la cual "fomenta el secreto y la ocultación, puesto que igual que reconoce la libertad a decir, también consagra el derecho a no decir, a callar lo que se considera privado" (Alberca, 2007, p. 104). A ese respecto, el propio autor ha declarado que "Me interesa escarbar en el secreto familiar [...] me interesa lo que no se ha dicho, lo que está en el sótano de la conciencia" (en Chaves-Espinach, 29/08/2013, p. 15), sin preocuparse en rellenar lo no dicho.

10. Con la excepción de algunos miembros consanguíneos puntuales -la tía Nena, el abuelo José Enrique Expósito...- y otros políticos -la esposa del abuelo Angélica, el tío Fernando García, Mariana...-, puesto que Larga noche... cuestiona la consanguinidad como lazo. 
11. Procedimiento usual en la narrativa del siglo XX que transforma la novela decimonónica por cuanto plantea que del personaje principal no se conoce ni su nombre o sólo la inicial (como K. de El castillo de Kafka), como parece proponerlo Cortés con uno decisivo en su texto.

12. En esa dialéctica de términos transicionales importantes como la compulsión de repetición según Welchmann, de carácter ambivalente porque implica el narcisismo y la muerte (citado en Brea, 2005, pp. 213-214).

13. Y que se materializaba en hechos concretos como la aprobación al derecho al voto en Costa Rica el mismo año de publicación de la novela.

14. Aunque no, como se dijo, contextual en virtud de "la orientación didáctica del cuarenta" (Ovares et ál., 1993, p. 267).

15. En efecto, la función afectiva no es terreno exclusivo de un género, lo contrario, como termina sucediendo con La ruta..., implica contribuir al asentamiento de nuevo de la lógica patriarcal.

16. El discurso final es de una complejidad polifónica en la que se disuelven tanto el narrador -en las marcas deícticas, en la puntuación- destinado a apuntar a la misma operación sobre las identidades -del hijo, de la madre, en las de un espacio imposible de ser delimitado-, un recurso más próximo en la narrativa costarricense al ser puesto en práctica por Virgilio Mora.

\section{Bibliografía}

Alberca, M. (2007). El pacto autobiográfico. De la novela autobiográfica a la autoficción. Madrid: Biblioteca Nueva.

Chase, A. (2006, 3 de julio). Yolanda Oreamuno: contra el olvido. Tribuna democrática. http://www.tribunademocratica.com/2006/07/yolanda_oreamuno_contra_el_olvido/ [Consulta 26 de noviembre de 2014].

Chaves-Espinach, F. (2013, 29 de agosto). Carlos Cortés explora sus fantasmas. La Nación, Viva/Letras, 15.

Cortés, C. (1999). Cruz de olvido. San José: Alfagura.

Cortés, C. (2013). Larga noche hacia mi madre. San José: Alfaguara.

Cortés, J. M. G. (1997). Orden y caos. Un estudio cultural sobre lo monstruoso en el arte. Barcelona: Anagrama.

Franco, J. (1986). Apuntes sobre la crítica feminista y la literatura hispanoamericana. Hispamérica. 45 (15), 31-43.

Freud, S. (1976). Lo siniestro. Argentina: López Crespo.

Harari, R. (1988). Polifonías del arte en psicoanálisis. Barcelona: Ediciones del Serbal.

Hock-Soon Ng, A. (2004). Dimensions of Monstrosity in Contemporary Narratives. New York: Palgrave MacMillan.

Mackenbach, W. (2007). YO o las trampas de la biografía. Revista de Filología y Lingúística. 33 (2), 11-22.

Oreamuno, Y. (2010). La ruta de su evasión. (3 ed.). San José: Editorial Costa Rica.

Oreamuno, Y. (2011). A lo largo del corto camino. (2 ed.). San José: Editorial Costa Rica.

Ovares, F. et ál. (1993). La casa paterna. Escritura y nación en Costa Rica. San José: Editorial de la Universidad de Costa Rica. 
Quesada, Á. (2012). Breve historia de la literatura costarricense. San José: Editorial Costa Rica. Ramírez, S. (2011). La fugitiva. San José: Santillana/Alfaguara.

Robles-Mohs, I. (1988). Un nuevo modo de narrar: La ruta de su evasión de Yolanda Oreamuno. Káñina. Revista de Artes y Letras de la Universidad de Costa Rica. 12 (1), 49-53.

Rojas, M. y Ovares, F. (1995). 100 años de literatura costarricense. San José: FARBEN.

Sanabria, C. (2013, 27 de octubre). A una madre que se odia: Larga noche hacia mi madre de Carlos Cortés. La Nación, Suplemento Áncora, 11.

de Vallbona, R. (1987). La ruta de su evasión, de Yolanda Oreamuno: escritura proustiana suplementada. Revista Iberoamericana. 53, 193-217.

Welchman, J. C. (2005). Sobre lo siniestro en la cultura visual. Por J. L. Brea (Ed.). Estudios visuales. La epistemología de la visualidad en la era de la globalización. (207-221). Madrid: Akal. 
